\title{
Cognitive outcome in congenital central hypothyroidism: a systematic review with meta-analysis of individual patient data
}

\section{J C Naafs', L M Vendrig ${ }^{1}$, J Limpens ${ }^{2}$, H J van der Lee ${ }^{3}$, R G Duijnhoven ${ }^{4}$, J P Marchal ${ }^{5}$, A S van Trotsenburg ${ }^{1}$ and N Zwaveling-Soonawala'}

${ }^{1}$ Department of Pediatric Endocrinology, Emma Children's Hospital, Amsterdam UMC, University of Amsterdam, Amsterdam, Netherlands, ${ }^{2}$ Medical Library, Amsterdam UMC, University of Amsterdam, Amsterdam, Netherlands, ${ }^{3}$ Pediatric Clinical Research Office, Amsterdam UMC, University of Amsterdam, Amsterdam, Netherlands, ${ }^{4}$ Department of Obstetrics and Gynaecology, Amsterdam UMC, University of Amsterdam, Amsterdam, Netherlands, and ${ }^{5}$ Pediatric Psychosocial Department, Emma Children's Hospital, Amsterdam UMC, University of Amsterdam, Amsterdam, Netherlands

Correspondence should be addressed to $\mathrm{N}$ Zwaveling-Soonawala Email

n.zwaveling@

amsterdamumc.nl

\section{Abstract}

Objective: To provide an overview of cognitive and motor outcome, and quality of life (QoL) in patients with congenital central hypothyroidism (CH-C).

Design: Systematic review with individual patient data (IPD) meta-analysis.

Methods: OVID MEDLINE, EMBASE and PsycInfo were searched from inception to June 11th, 2019. Studies in patients with $\mathrm{CH}-\mathrm{C}$, either isolated or with multiple pituitary hormone deficiency (MPHD), were included if $\mathrm{CH}-\mathrm{C}$ patients could be separated from any additional patient groups. Primary outcomes were full-scale intelligence quotient (FSIQ) and motor outcome; secondary outcome was QoL. Following data-extraction, one-stage IPD meta-analysis was performed, fitting a linear mixed model with FSIQ as dependent variable. Random intercepts were fitted for each study. Results: Six studies measuring FSIQ were eligible for meta-analysis, comprising $30 \mathrm{CH}-\mathrm{C}$ patients (20 males; $27 \mathrm{MPHD}$ patients). FSIQ range was wide (64-123). Mean weighted FSIQ was 97 (95\% Cl: 88-105). Twenty-seven percent had an FSIQ below 85 ( $\geq 1$ s.D. below norm score), and 10\% below 70 ( $\geq 2$ s.D. below norm score). There was no significant association between FSIQ and sex or age. Age at treatment initiation was available from three studies only, thus impeding a reliable analysis of this parameter. Motor outcome and QoL were each studied in one study; no quantitative analyses could be performed for these outcomes.

Conclusion: A wide range in FSIQ scores was observed in $\mathrm{CH}-\mathrm{C}$ patients. Results should be interpreted with caution, because included patients mainly had MPHD and age at treatment initiation was unknown for the majority of patients.

\section{Introduction}

Thyroid hormone is indispensable for normal pre- and postnatal brain development, and untreated congenital hypothyroidism $(\mathrm{CH})$ leads to permanent intellectual and motor disability. Because early detection and treatment of $\mathrm{CH}$ prevents developmental disability, neonatal screening programs for $\mathrm{CH}$ have been implemented worldwide since the late 1970 s $(1,2)$.

$\mathrm{CH}$ may be of thyroidal (CH-T) or central, i.e. hypothalamic-pituitary, origin ( $\mathrm{CH}-\mathrm{C})$. $\mathrm{CH}-\mathrm{T}$ is much more prevalent than $\mathrm{CH}-\mathrm{C}$ ( 1 per 3000 vs 1 per 16,000
Published by Bioscientifica Ltd. 
live births) (3). Most neonatal screening programs aim at detecting $\mathrm{CH}-\mathrm{T}$ and do not detect $\mathrm{CH}-\mathrm{C}$ (4). Few countries use a screening program that detects both $\mathrm{CH}-\mathrm{T}$ and $\mathrm{CH}-\mathrm{C}$, for example, the Netherlands, Israel and parts of Japan, Italy and the United States $(4,5,6,7,8)$.

It can be hypothesized that $\mathrm{CH}-\mathrm{C}$ and $\mathrm{CH}-\mathrm{T}$ patients face a similar risk for developmental disability. Contrary to the frequent assumption that the severity of hypothyroidism is only mild in $\mathrm{CH}-\mathrm{C}$, we showed that more than half of $\mathrm{CH}-\mathrm{C}$ patients have moderate-to-severe hypothyroidismintheneonatalphase, requiringimmediate treatment to prevent brain damage (9). Furthermore, in approximately two thirds of patients $\mathrm{CH}-\mathrm{C}$ is part of multiple pituitary hormone deficiency (MPHD) (10). MPHD provides an additional risk for developmental disability, because central adrenal insufficiency and/or growth hormone deficiency (GHD) may lead to brain damaging hypoglycemia and circulatory shock $(4,11)$. Finally, quality of life (QoL) may also be impaired, as has been observed in patients with $\mathrm{CH}-\mathrm{T}$, as well as in patients with childhood-onset hypopituitarism $(12,13)$.

Cognitive outcome of early treated $\mathrm{CH}-\mathrm{T}$ patients has been studied extensively $(2,14,15,16,17)$. However, outcome studies in both early and late treated $\mathrm{CH}-\mathrm{C}$ patients are scarce, and an overview of studies is lacking. Furthermore, it remains unknown whether early detection by neonatal screening and subsequent early treatment of $\mathrm{CH}-\mathrm{C}$ patients improves cognitive outcome when compared with late diagnosed and treated $\mathrm{CH}-\mathrm{C}$ patients.

To provide an overview of the currently reported cognitive and motor outcomes, and QoL in CH-C patients, whether treated early or late, we conducted a systematic review and individual patient data (IPD) metaanalysis. For this review and meta-analysis we included both patients with isolated $\mathrm{CH}-\mathrm{C}$ and patients with $\mathrm{CH}-\mathrm{C}$ within the framework of MPHD.

\section{Methods}

The systematic review protocol was registered in the PROSPERO database (registration number CRD42018111543). Preferred Reporting Items for Systematic Reviews and Meta-Analyses (PRISMA) guidelines were used to report this systematic review (18).

\section{Participants}

Studies in children or adults with $\mathrm{CH}-\mathrm{C}$ were included. Although $\mathrm{CH}-\mathrm{C}$ is often diagnosed in childhood, we allowed studies in adult patients, not only to review cognitive outcome throughout life, but also to prevent exclusion of useful studies for this low-prevalence disease. Studies including $\mathrm{CH}-\mathrm{C}$ patients as well as other patient groups, for example, $\mathrm{CH}-\mathrm{T}$ or GHD patients, were only included if $\mathrm{CH}-\mathrm{C}$ patient data could be extracted separately. If $\mathrm{CH}$ etiology was unknown, authors were contacted by email. If the study did not meet the inclusion criteria or the etiology remained unclear, the study was excluded. Since neurocognitive tests allow for comparison to population norm scores, both studies with and without control groups were allowed.

\section{Outcomes}

The primary outcomes for this study were cognitive outcome, assessed using full-scale intelligence quotient (FSIQ), and motor outcome. Secondary outcome was QoL. Studies using a validated neurocognitive test, motor test or QoL-questionnaire were included. Regarding motor function, studies with tests for gross and fine motor skills were both accepted.

Studies reporting mean FSIQ \pm S.D. were considered eligible and authors were requested to provide IPD. Patients with an estimated FSIQ, for example, due to failure to complete a test, were not included in IPD metaanalysis.

\section{Study design}

Prospective and retrospective cohort studies, case-control studies and other types of observational studies were included.

\section{Study identification and selection}

A medical information specialist (JL) performed an exhaustive search in MEDLINE, EMBASE and PsycInfo (all via the OVID interface) from inception to June $11^{\text {th }}, 2019$, using thesaurus terms (i.e. MeSH-terms in MEDLINE) and textwords. No date or language restrictions were applied. A pilot search revealed that a search for central hypothyroidism and outcomes missed many relevant papers, because origin of disease ('central') or measured outcomes were not explicitly mentioned in title or abstract. Therefore several (sub)searches were constructed:

1. Searches for [A] central hypothyroidism, pituitary dwarfism, hypopituitarism in children; [B] hypothyroidism/thyroid hormone (deficiency) and 
pituitary diseases/pituitary hormone (deficiency) and [C] a narrow search for congenital hypothyroidism, were all combined with a search filter for children and a broad search for cognitive, intellectual, motor outcomes and QoL.

2. A narrow search (title or major MeSH) for congenital central hypothyroidism was combined with a childfilter only, not with terms for outcomes.

We cross-checked the reference lists of identified relevant papers in Web of Science and adapted the search in case of additional relevant studies. The bibliographic records retrieved were imported and de-duplicated using Endnote (Clarivate Analytics, Philadelphia, USA; https://www. endnote.com). The complete search strategy is shown in Supplementary File 1 (See section on supplementary materials given at the end of this article). All papers were screened based on title and abstract by two reviewers independently (JCN and LMV). Selected studies were reviewed full text by both reviewers to decide on in- or exclusion. Discrepancies between reviewers were solved by discussion or consulting a third reviewer (NZ). To document the study selection process, references were imported into Covidence online software (Veritas Health Innovation, Melbourne, Australia; https://www. covidence.org).

\section{Data extraction}

Data extraction from selected studies was performed by two reviewers independently (JCN and LMV), using a prespecified form. The following variables were included: age, sex, gestational age, (parental) ethnicity, educational status, age at diagnosis, comorbidities (especially MPHD), FSIQ, scores of motor assessment and scores from QoL questionnaires. If IPD could not be obtained from the original publication, authors were contacted via e-mail with a request to share IPD.

IPD were checked for completeness by two reviewers (JCN and LMV). If data were incomplete, original authors were contacted again to provide additional information.

\section{Risk of bias assessment}

Risk of bias was assessed with the Newcastle-Ottawa Scale (NOS) for Quality Assessment. Since the NOS is not suitable for cross-sectional studies, adapted scales have been created (19). We adapted the NOS scale for cross-sectional studies for our research question (Supplementary File 2).

\section{Data synthesis and statistical analysis}

Statistical heterogeneity between studies was assessed using the E-statistic (energy) test for equality of multivariate distributions. Given the limited power of such tests, a $P$ value for the test of heterogeneity $<0.10$ was considered to indicate a high likelihood of heterogeneity. One-stage IPD meta-analysis was performed, using a linear mixed model with FSIQ as dependent variable. Random intercepts were fitted for each study. Maximum likelihood was used for parameter estimation. Patient characteristics such as age and sex were added to the model as fixed effects, to study the association between age or sex and FSIQ. Fit of the models was compared using the Akaike Information Criterion (AIC) and one-way ANOVA. We planned to compare outcomes between MPHD patients and isolated $\mathrm{CH}-\mathrm{C}$ patients if both subgroups were represented sufficiently within the dataset. A binomial test was used to compare the number of $\mathrm{CH}-\mathrm{C}$ patients with an FSIQ below 85 ( $\geq 1$ s.D. below population norm score) or below 70 ( $\geq 2$ s.D. below population norm score) to population norm scores. Descriptive analyses, statistical tests and meta-analysis were performed with RStudio, version 3.6.1 (2019-07-05), using packages energy and lme4 $(20,21,22)$.

\section{Results}

The literature search yielded 885 unique articles of which 188 articles underwent full text review. The study selection process was performed for each outcome independently; the selection process for FSIQ is shown in Fig. 1. Thirteen studies included $\mathrm{CH}-\mathrm{C}$ patients, but seven of these studies were excluded because $\mathrm{CH}-\mathrm{C}$ patient data could not be extracted separately $(23,24,25,26,27,28,29)$. From the study by Bucher et al., only aggregate data could be obtained because original data were no longer available (29). In addition, nine out of 33 patients had an estimated FSIQ which had been 'empirically rated [by authors] based on educational achievement', for example, a patient attending a 'normal school' was assigned an FSIQ of 100 (29). Although remaining FSIQs were measured with validated tests, aggregate data from this study were considered low quality evidence and the study was excluded from meta-analysis.

For the primary outcome FSIQ, six studies were eligible for extraction of IPD $(30,31,32,33,34,35)$. Next, all studies identified in the search were screened for the primary outcome motor functioning. However, motor 


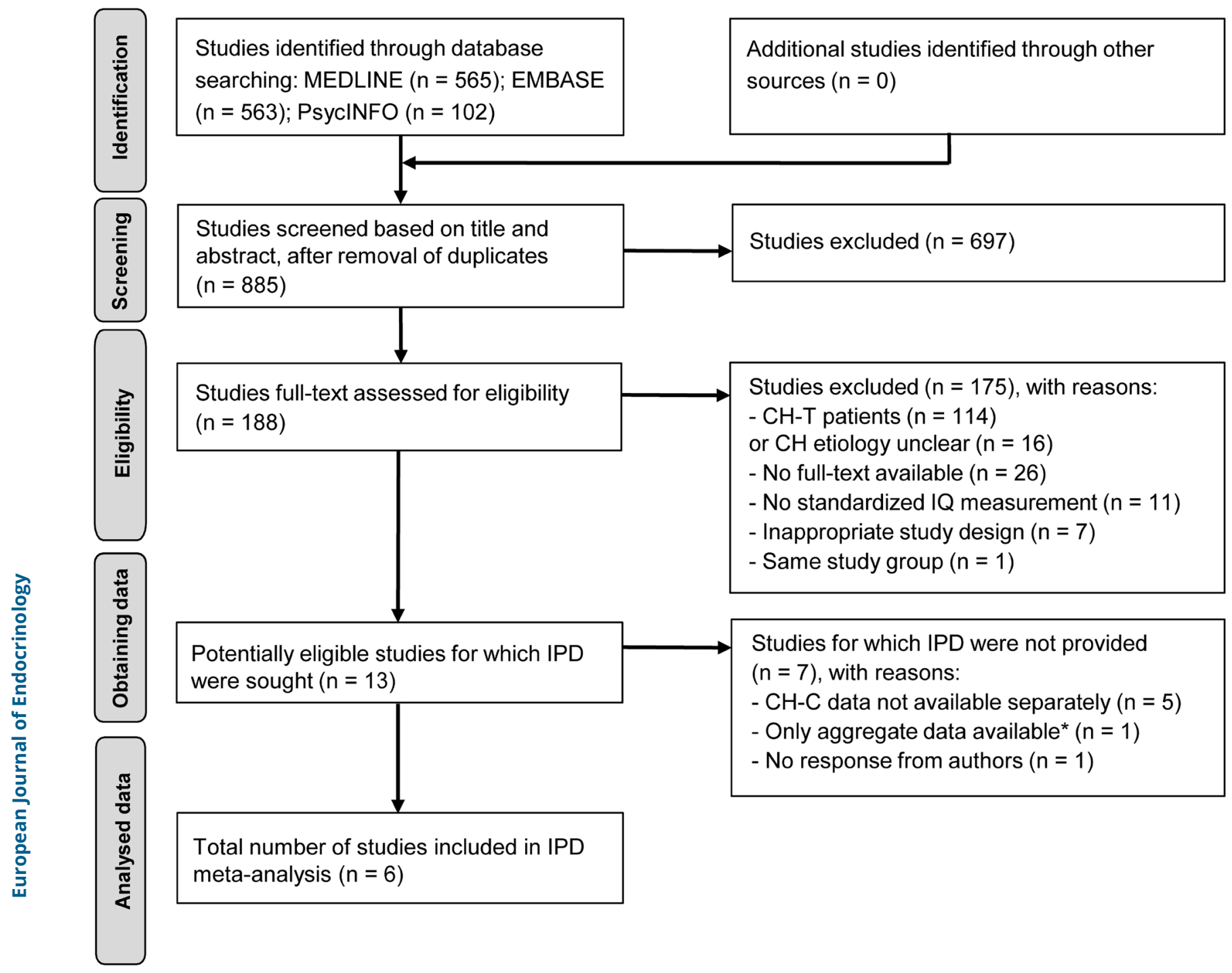

Figure 1

Study selection process for primary outcome full-scale intelligence quotient, reported using the PRISMA IPD flow diagram. Abbreviations: $\mathrm{CH}$, congenital hypothyroidism; $\mathrm{CH}-\mathrm{C}$, congenital hypothyroidism of central origin; $\mathrm{CH}-\mathrm{T}$, congenital hypothyroidism of thyroidal origin; IPD, individual patient data; IQ, intelligence quotient.

functioning was evaluated in one study only and thus no meta-analysis was performed for this part of the primary outcome. The study selection for motor function is shown in Supplementary File 3.

For the secondary outcome QoL five potentially eligible studies were identified $(13,36,37,38,39)$. Four studies were excluded because data of $\mathrm{CH}-\mathrm{C}$ patients could not be obtained separately. IPD on QoL could be retrieved from one study only (39). An overview of eligible studies for which authors did not provide IPD is presented in Supplementary Table 1. The complete risk of bias assessment is shown in Supplementary Table 2.

\section{Study characteristics}

IPD regarding the primary outcome FSIQ was obtained from six studies: Pollitt et al. (30), Rosenbloom et al. (32), Frankel et al. (31), Rosenbloom et al. (32), Meyer-Bahlburg et al. (33), Karges et al. (34) and Kempers et al. (35). Characteristics of included studies are presented in Table 1.

In total, $30 \mathrm{CH}-\mathrm{C}$ patients (20 males) were eligible for inclusion in IPD meta-analysis (Table 2). Age of the included patients ranged from 3 to 21 years, with a mean age of $12.9 \pm 4.3$ years. The majority of patients had MPHD (27/30, 90\%). Information regarding age at start of 
Table 2 Overview of patients included in individual patient data meta-analysis.

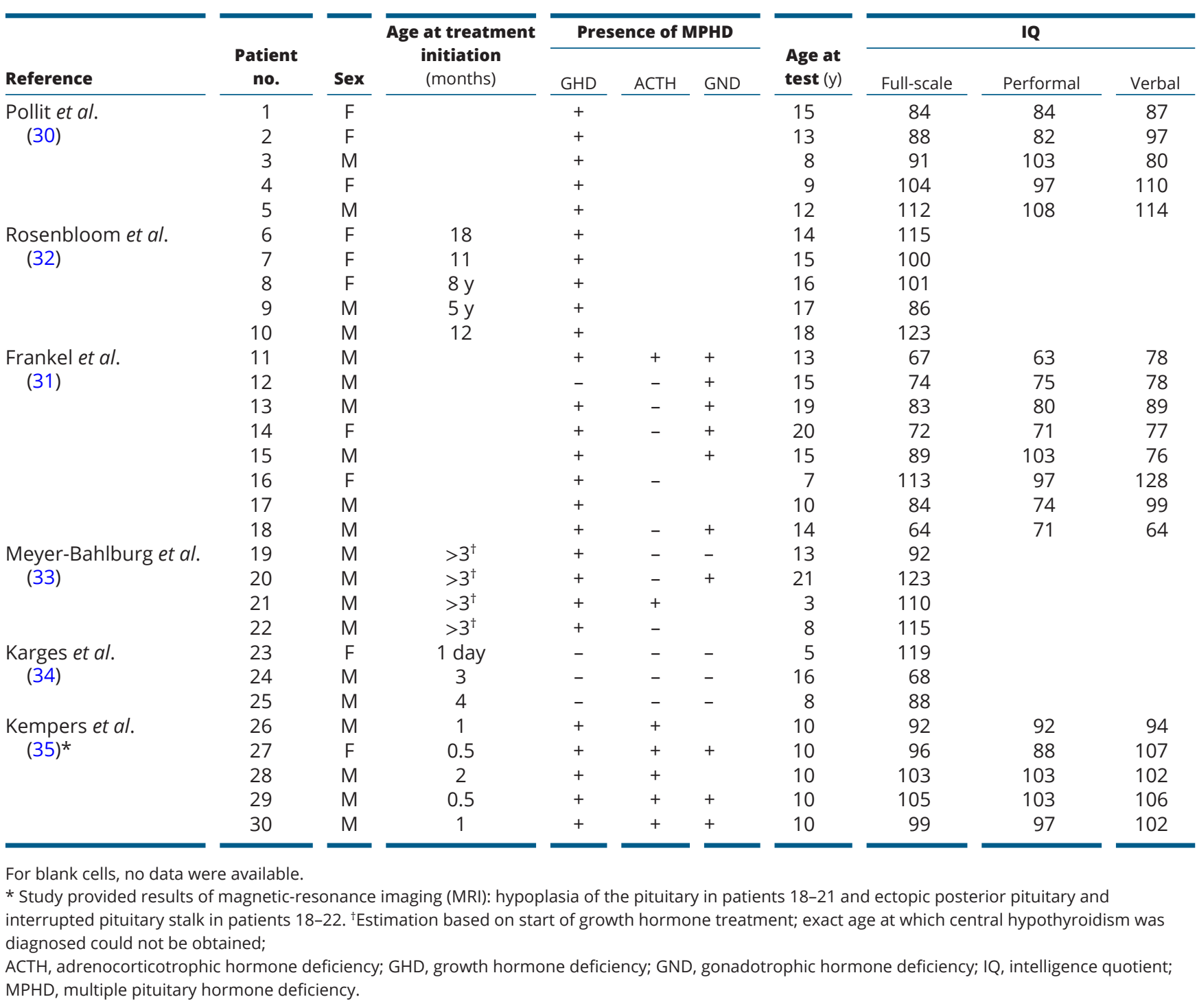

mean FSIQ and 95\% CI remain within population norm scores - the sensitivity analysis does indicate this study is driving the tendency toward a lower FSIQ.

\section{Motor outcome}

Motor outcome was assessed in one study. Kempers et al. used the Movement Assesment Battery for Children to evaluate motor outcome in five $\mathrm{CH}-\mathrm{C}$ patients included in their study (35). Among these patients, one had a normal total motor impairment score, indicating no motor problems. Four had an abnormal score, indicating borderline motor problems in one patient and definite motor problems in three patients. All $\mathrm{CH}-\mathrm{C}$ patients in this study had MPHD and had treatment started before the age of 2 months.

\section{Secondary outcome: quality of life}

For the secondary outcome QoL, data from one study could be obtained. Joustra et al. studied health-related QoL in 15 adult male patients with isolated $\mathrm{CH}-\mathrm{C}$ caused by IGSF1 deficiency syndrome using the Short Form-36 (SF-36) questionnaire (39). When compared with 191 healthy controls, no significant differences were found.

\section{Discussion}

To our best knowledge, this is the first systematic review reporting on cognitive outcome in $\mathrm{CH}-\mathrm{C}$. Information on primary outcome FSIQ could be obtained from 30 patients (three isolated $\mathrm{CH}-\mathrm{C} ; 27 \mathrm{CH}-\mathrm{C}$ within the framework of $\mathrm{MPHD}$ ) from six studies. Although the FSIQ in $\mathrm{CH}-\mathrm{C}$ 


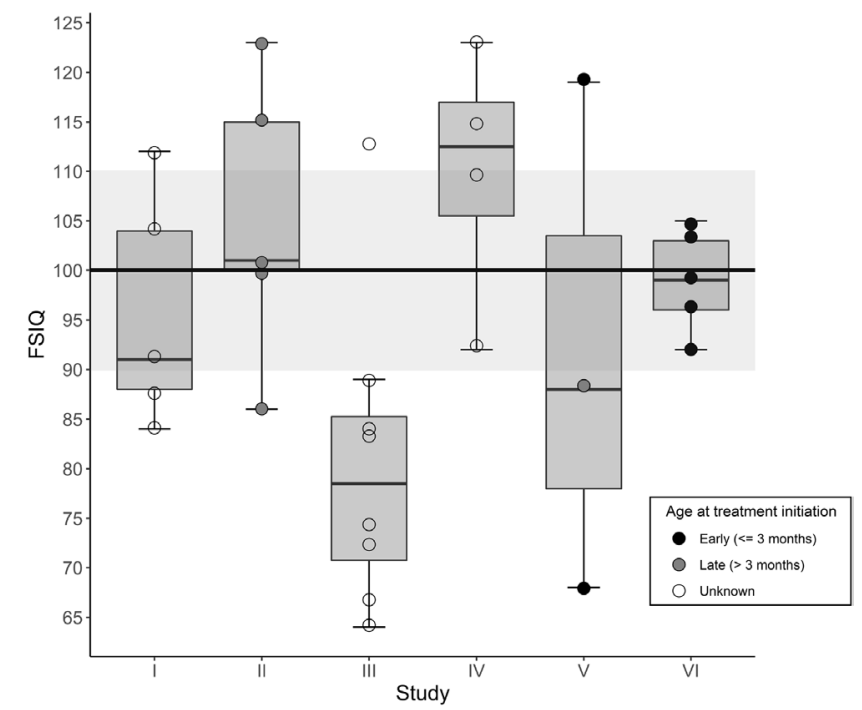

\section{Figure 2}

Box-plot of the full-scale intelligence quotient in $\mathrm{CH}-\mathrm{C}$ patients included in individual patient data meta-analysis. Lower and upper box limits represent 25th and 75th percentile; line in the box represents the median; lower and upper error bars represent the minimum and maximum value, except for study III, where the maximum value is represented by a dot. Horizontal reference area displays mean FSIQ in general population, with 25th and 75th percentile. Study numbers: I, Pollitt et al.; II, Rosenbloom et al.; III, Frankel et al.; IV, MeyerBahlburg et al.; V, Karges et al.; VI, Kempers et al. Abbreviations: $\mathrm{CH}-\mathrm{C}$, congenital hypothyroidism of central origin; FSIQ; full-scale intelligence quotient.

patients (mean: 97, 95\% CI: 88-105) is comparable to the population norm score (mean FSIQ: 100, s.D. 15), a wide FSIQ range was seen, which appeared to be shifted toward lower values. An FSIQ below 70 ( $\geq 2$ s.D. below norm score) occurred significantly more often in $\mathrm{CH}-\mathrm{C}$ patients than would be expected in the general population.

Since age at start of treatment was unknown for the majority of patients, we could not compare early and late treated $\mathrm{CH}-\mathrm{C}$ patients. Furthermore, a reliable comparison between isolated $\mathrm{CH}-\mathrm{C}$ and MPHD patients was not possible, as the majority of patients had MPHD. The underrepresentation of isolated $\mathrm{CH}-\mathrm{C}$ patients was not unexpected since it has been reported that $66-98 \%$ of $\mathrm{CH}-\mathrm{C}$ patients have MPHD $(10,40,41)$. This reflects clinical practice in countries using a neonatal screening method that detects $\mathrm{CH}-\mathrm{C}$, where most detected patients have MPHD and only a minority has isolated $\mathrm{CH}-\mathrm{C}(6,7,40)$.

Previous studies have suggested that cognitive outcome in $\mathrm{CH}-\mathrm{C}$ patients, especially those with MPHD, may be impaired. Nebesio et al. performed a large, retrospective study in $42 \mathrm{CH}-\mathrm{C}$ patients (98\% MPHD) (41). Clinical characteristics were evaluated, including the presence of developmental delay. Medical charts were used to assign developmental delay, which was based on parental report, visits to a developmental pediatrician or involvement in early intervention therapies (personal communication with author). Developmental delay was seen in 50\% (21/42) of the patients. When comparing patients detected in neonatal screening to those detected clinically later in life, developmental delay was seen in $25 \%(2 / 8)$ of early-detected versus $56 \%(19 / 34)$ of late detected patients. Early-detected patients had a mean time to endocrine consultation of 4.6 months, while late-detected patients had a mean time to endocrine consultation of 16.9 months (41). While this is the only study comparing early versus late treated $\mathrm{CH}-\mathrm{C}$ patients with regard to developmental outcome, the study was excluded during the study selection because no validated neurocognitive test was used (Fig. 1).

Brown etal. reported a below average FSIQ in 10 children with congenital hypopituitarism (seven with MPHD including $\mathrm{CH}-\mathrm{C}$, three with isolated $\mathrm{GH}$ deficiency) (27). Mean FSIQ in these patients was 75 (95\% CI: 70-80). Since the patient group also included three cases of isolated GHD and original data were no longer available, data on $\mathrm{CH}-\mathrm{C}$ patients could not be extracted separately (personal communication with author). The study was therefore not eligible for our meta-analysis (Supplementary Table 2). It is interesting to note that all seven cases of MPHD had hypoglycemia at initial presentation which may have influenced brain development.

Bucher et al. studied intellectual and school performances of 33 late-treated $\mathrm{CH}-\mathrm{C}$ patients, all with MPHD (29). Intelligence was measured using a validated test in most patients, but nine out of 33 patients had an estimated FSIQ based on their educational level. A patient attending a 'normal school' was assigned an FSIQ of 100, while patients attending college or university were assigned FSIQs of 115 and 125, respectively (29). While the study reported a mean FSIQ of 103, this average must be interpreted with caution since an objective measurement was lacking in almost one-third of patients.

Beside the rather general concept of FSIQ, several components of cognitive functioning can be distinguished, for example, executive functioning, memory and visuospatial processing. Studies of such components in $\mathrm{CH}-\mathrm{C}$ are sparse, only one study could be identified. Joustra et al. studied executive functioning and memory in 15 adult male patients with isolated $\mathrm{CH}-\mathrm{C}$, due 
to IGSF1 deficiency (39). Patients were compared to 54 healthy controls. The study results suggest a mild deficit in attentional control in isolated CH-C patients, while no differences were found regarding memory (39). Although IGSF1 deficiency patients form a specific subgroup, IGSF1 deficiency is the most common genetic cause of isolated $\mathrm{CH}-\mathrm{C}$ and these results support the need for further research on specific cognitive functioning domains in all $\mathrm{CH}-\mathrm{C}$ patients (42).

In summary, corresponding with findings from our meta-analysis, previous studies not included in this meta-analysis also suggest cognitive impairment in $\mathrm{CH}-\mathrm{C}$ patients. However, no firm conclusion can be drawn from these studies, due to the lack of validated tests and separate data on $\mathrm{CH}-\mathrm{C}$ patients.

There are various reasons to expect impaired cognitive outcome in children with MPHD. First, MPHD may lead to hypoglycemia during the neonatal period, potentially causing brain damage and developmental disability later in life (40). Furthermore, neonatal thyroid hormone concentrations are known to be significantly lower in MPHD patients compared with isolated $\mathrm{CH}-\mathrm{C}$ patients, and more severe $\mathrm{CH}$ has been associated with lower IQ scores $(43,44)$. Still, the presence of additional hormone deficiencies makes it difficult to delineate the precise role of thyroid hormone deficiency in the cognitive outcome in this subgroup of patients. It is expected, though, that $\mathrm{CH}-\mathrm{C}$ patients benefit from early treatment for both their hypothyroidism and additional hormone deficiencies. Therefore, adding detection of $\mathrm{CH}-\mathrm{C}$ to more neonatal screening programs has been suggested $(45,46)$. Unfortunately, this systematic review does not answer the question whether early detection of $\mathrm{CH}-\mathrm{C}$ is superior to clinical case detection with regard to cognitive outcome.

Besides cognition, motor function is also known to be impaired in children with severe $\mathrm{CH}-\mathrm{T}$ and this impairment is associated with $\mathrm{CH}$ severity $(14,47)$. Because $\mathrm{CH}-\mathrm{C}$ patients have moderate-to-severe hypothyroidism in more than half of the cases (9), motor function was systematically reviewed as well, but only one study examined this. Kempers et al. studied motor function in $5 \mathrm{CH}-\mathrm{C}$ patients with MPHD, obtaining a score for manual dexterity, ball skills and balance (35). Motor impairment was seen in 4 out of 5 patients; all four patients had needed physical therapy during childhood. Despite the small sample size, these results indicate that clinical attention to motor function is necessary, and that further studies examining motor function in pediatric $\mathrm{CH}-\mathrm{C}$ patients are needed.
A strength of the current study is the number of included $\mathrm{CH}-\mathrm{C}$ patients, despite the low prevalence of the disease. Although 30 patients is still a small number, it is the largest group studied with validated tests until now. In addition IPD-meta-analysis could be performed, which allows detailed exploration of characteristics at the individual patient level (in this study age and sex), when compared with aggregate data meta-analysis (48). Finally, although various tests were used to assess FSIQ across the included studies, four out of six studies used a Wechsler test (Table 1). The remaining studies used the StanfordBinet test and Kaufman Assessment Battery for Children (K-ABC). Notwithstanding the variety in tests, we treated FSIQ as a homogeneous outcome given the generally high correlation of FSIQ across intelligence tests $(49,50)$.

Several limitations of the current study can be identified. Although information on additional hormone deficiencies was available, information on severity of hypothyroidism and age at treatment initiation was lacking for the majority of patients. In addition, while the used intelligence tests were homogeneous across studies, heterogeneity was seen on other levels. For instance, there was a wide range in publication dates of the included studies. Because we aimed to identify all available studies, no date restriction was applied. The wide range in publication dates may have led to clinical variability among patients, for example, in treatment received, as guidelines for CH-C have been established only recently (11). Another important point is selection bias. Pollitt et al. studied intelligence in some of the first pediatric patients receiving $\mathrm{GH}$, stating that 'preference was given to patients who the pediatricians thought were well-adjusted psychologically, and who also had cooperative parents, [so] that the program of treatment would be adhered to as scheduled' (30). This may have led to overestimation of the FSIQ and FSIQ range. Frankel et al. mainly included children from primarily Jewish oriental families (31). It has been assumed that these families were first generation immigrants, 'expected to perform poorly on culturally biased intelligence tests' (33). This might explain the results from the sensitivity analysis, showing a tendency toward a higher mean FSIQ when excluding results from Frankel et al.

With these limitations in mind, it remains unknown whether early detection of $\mathrm{CH}-\mathrm{C}$ is superior to clinical case detection regarding cognitive outcome. To answer the question whether cognitive outcome differs between early and late treated $\mathrm{CH}-\mathrm{C}$ patients, additional welldesigned and sufficiently large studies are needed. 
In the Netherlands $\mathrm{CH}-\mathrm{C}$ is detected through neonatal screening (3). We are currently performing a nationwide follow-up study on cognitive outcome in more than 80 early treated Dutch CH-C patients. In this study, we are including CH-C patients born between 1995 and 2015, detected through neonatal screening and able to complete an age-specific intelligence test. Results from this ongoing study will provide more evidence on cognitive outcome in patients with early treated $\mathrm{CH}-\mathrm{C}$. Meanwhile, studies determining cognitive outcome in late treated, clinically detected $\mathrm{CH}-\mathrm{C}$ patients are needed as well, in order to subsequently compare early and late detected patients.

In conclusion, we report a mean FSIQ of 97 in a group of $30 \mathrm{CH}-\mathrm{C}$ patients studied with IPD meta-analysis. An FSIQ below 70 was found in $10 \%$ of $\mathrm{CH}-\mathrm{C}$ patients. Although the current systematic review provides an overview of published data on cognitive outcome in $\mathrm{CH}-\mathrm{C}$ patients, results should be interpreted with caution due to the relatively small group of patients, heterogeneity of the study populations and missing data on disease severity and initiation of treatment. In order to obtain a complete overview of cognitive outcome in CH-C patients and answer the question whether early detection and treatment improves cognitive outcome, well-designed and sufficiently large studies are needed, including both isolated $\mathrm{CH}-\mathrm{C}$ patients and MPHD patients with $\mathrm{CH}-\mathrm{C}$, as well as early and late detected patients.

\section{Supplementary materials}

This is linked to the online version of the paper at https://doi.org/10.1530/ EJE-19-0874.

\section{Declaration of interest}

The authors declare that there is no conflict of interest that could be perceived as prejudicing the impartiality of this study.

\section{Funding}

This research did not receive any specific grant from any funding agency in the public, commercial or not-for-profit sector.

\section{Author contribution statement}

A S van Trotsenburg and N Zwaveling-Soonawala: contributed equally to this work.

\section{References}

1 Klein AH, Meltzer S \& Kenny FM. Improved prognosis in congenital hypothyroidism treated before age three months. Journal of Pediatrics 197281 912-915. (https://doi.org/10.1016/s0022-3476(72)80542-0)
2 New England Congenital Hypothyroidism Collaborative. Effects of neonatal screening for hypothyroidism: prevention of mental retardation by treatment before clinical manifestations. Lancet 1981 2 1095-1098. (https://doi.org/10.1016/S0140-6736(81)91287-3)

3 Lanting CI, van Tijn DA, Loeber JG, Vulsma T, de Vijlder JJ \& Verkerk PH. Clinical effectiveness and cost-effectiveness of the use of the thyroxine/thyroxine-binding globulin ratio to detect congenital hypothyroidism of thyroidal and central origin in a neonatal screening program. Pediatrics 2005116 168-173. (https://doi. org/10.1542/peds.2004-2162)

4 Ford G \& LaFranchi SH. Screening for congenital hypothyroidism: a worldwide view of strategies. Best Practice and Research: Clinical Endocrinology and Metabolism 201428 175-187. (https://doi. org/10.1016/j.beem.2013.05.008)

5 Tenenbaum-Rakover Y, Almashanu S, Hess O, Admoni O, HagDahood Mahameed A, Schwartz N, Allon-Shalev S, Bercovich D $\&$ Refetoff S. Long-term outcome of loss-of-function mutations in thyrotropin receptor gene. Thyroid 201525 292-299. (https://doi. org/10.1089/thy.2014.0311)

6 Fujiwara F, Fujikura K, Okuhara K, Tsubaki J, Fukushi M, Fujita K, Fujieda K \& Tajima T. Central congenital hypothyroidism detected by neonatal screening in Sapporo, Japan (2000-2004): it's prevalence and clinical characteristics. Clinical Pediatric Endocrinology 200817 65-69. (https://doi.org/10.1297/cpe.17.65)

7 Zamboni G, Zaffanello M, Rigon F, Radetti G, Gaudino R \& Tato L. Diagnostic effectiveness of simultaneous thyroxine and thyroid-stimulating hormone screening measurements. Thirteen years' experience in the Northeast Italian Screening Programme. Journal of Medical Screening 200411 8-10. (https://doi. org/10.1177/096914130301100103)

8 Kilberg MJ, Rasooly IR, LaFranchi SH, Bauer AJ \& Hawkes CP. Newborn screening in the US may Miss Mild persistent hypothyroidism. Journal of Pediatrics 2018192 204-208. (https://doi. org/10.1016/j.jpeds.2017.09.003)

9 Zwaveling-Soonawala N, van Trotsenburg AS \& Verkerk PH. The severity of congenital hypothyroidism of central origin should not be underestimated. Journal of Clinical Endocrinology and Metabolism 2015100 E297-E300. (https://doi.org/10.1210/jc.2014-2871)

10 Zwaveling-Soonawala N, Naafs JC, Verkerk PH \& van Trotsenburg ASP. Mortality in children With early-detected congenital central hypothyroidism. Journal of Clinical Endocrinology and Metabolism 2018103 3078-3082. (https://doi.org/10.1210/ jc.2018-00629)

11 Persani L, Brabant G, Dattani M, Bonomi M, FeldtRasmussen U, Fliers E, Gruters A, Maiter D, Schoenmakers N \& van Trotsenburg ASP. 2018 European Thyroid Association (ETA) guidelines on the diagnosis and management of central hypothyroidism. European Thyroid Journal 20187 225-237. (https:// doi.org/10.1159/000491388)

12 van der Sluijs Veer L, Kempers MJ, Maurice-Stam H, Last BF, Vulsma T \& Grootenhuis MA. Health-related quality of life and self-worth in 10-year old children with congenital hypothyroidism diagnosed by neonatal screening. Child and Adolescent Psychiatry and Mental Health 20126 32. (https://doi.org/10.1186/1753-2000-6-32)

13 Kao KT, Stargatt R \& Zacharin M. Adult quality of life and psychosocial outcomes of childhood onset hypopituitarism. Hormone Research in Paediatrics 201584 94-101. (https://doi. org/10.1159/000430863)

14 Kooistra L, Laane C, Vulsma T, Schellekens JM, van der Meere JJ \& Kalverboer AF. Motor and cognitive development in children with congenital hypothyroidism: a long-term evaluation of the effects of neonatal treatment. Journal of Pediatrics 1994124 903-909. (https:// doi.org/10.1016/s0022-3476(05)83178-6)

15 van der Sluijs Veer L, Kempers MJ, Wiedijk BM, Last BF, Grootenhuis MA \& Vulsma T. Evaluation of cognitive and motor development in toddlers with congenital hypothyroidism 
diagnosed by neonatal screening. Journal of Developmental and Behavioral Pediatrics 201233 633-640. (https://doi.org/10.1097/ DBP.0b013e3182690727)

16 Seo MK, Yoon JS, So CH, Lee HS \& Hwang JS. Intellectual development in preschool children with early treated congenital hypothyroidism. Annals of Pediatric Endocrinology and Metabolism 201722 102-107. (https://doi.org/10.6065/apem.2017.22.2.102)

17 Aleksander PE, Bruckner-Spieler M, Stoehr AM, Lankes E, Kuhnen P, Schnabel D, Ernert A, Stablein W, Craig ME, Blankenstein O et al. Mean high-dose 1-thyroxine treatment is efficient and safe to achieve a normal IQ in young adult patients with congenital hypothyroidism. Journal of Clinical Endocrinology and Metabolism 2018 103 1459-1469. (https://doi.org/10.1210/jc.2017-01937)

18 Stewart LA, Clarke M, Rovers M, Riley RD, Simmonds M, Stewart G, Tierney JF \& PRISMA-IPD Development Group. Preferred reporting items for systematic review and meta-analyses of individual participant data: the PRISMA-IPD statement. JAMA $20153 \mathbf{3 1 3}$ 1657-1665. (https://doi.org/10.1001/jama.2015.3656)

19 Herzog R, Alvarez-Pasquin MJ, Diaz C, Del Barrio JL, Estrada JM \& Gil Á. Are healthcare workers' intentions to vaccinate related to their knowledge, beliefs and attitudes? A systematic review. BMC Public Health 201313 154. (https://doi.org/10.1186/1471-2458-13-154)

20 R Core Team. R: A Language and Environment for Statistical Computing: Vienna, Austria: R Foundation for Statistical Computing 2018.

21 Rizzo M \& Szekely G. Energy: E-Statistics: Multivariate Inference via the Energy of Data. R Package Version 1.7-5 2018 ed.

22 Bates D, Maechler M, Bolker B \& Walker S. Fitting linear mixedeffects models using lme4. Journal of Statistical Software 201567 1-48. (https://doi.org/10.18637/jss.v067.i01)

23 Steinhausen HC \& Stahnke N. Negative impact of growth-hormone deficiency on psychological functioning in dwarfed children and adolescents. European Journal of Pediatrics 1977126 263-270. (https:// doi.org/10.1007/bf00477052)

24 Abbott D, Rotnem D, Genel M \& Cohen DJ. Cognitive and emotional functioning in hypopituitary short-statured children. Schizophrenia Bulletin 1982 8 310-319. (https://doi.org/10.1093/schbul/8.2.310)

25 Frisch H, Hausler G, Lindenbauer S \& Singer S. Psychological aspects in children and adolescents with hypopituitarism. Acta Paediatrica Scandinavica 199079 644-651. (https://doi. org/10.1111/j.1651-2227.1990.tb11529.x)

26 Connelly JF, Rickards AL, Coakley JC, Price GJ, Francis I, Mathur KS \& Wolfe R. Newborn screening for congenital hypothyroidism, Victoria, Australia, 1977-1997. Part 2: treatment, progress and outcome. Journal of Pediatric Endocrinology and Metabolism $2001 \mathbf{1 4}$ 1611-1634. (https://doi.org/10.1515/jpem.2001.14.9.1611)

27 Brown K, Rodgers J, Johnstone H, Adams W, Clarke M, Gibson M $\&$ Cheetham T. Abnormal cognitive function in treated congenital hypopituitarism. Archives of Disease in Childhood 200489 827-830. (https://doi.org/10.1136/adc.2003.029116)

28 Signorini SG, Decio A, Fedeli C, Luparia A, Antonini M, Bertone C, Misefari W, Ruberto G, Bianchi PE \& Balottin U. Septo-optic dysplasia in childhood: the neurological, cognitive and neuroophthalmological perspective. Developmental Medicine and Child Neurology 201254 1018-1024. (https://doi.org/10.1111/j.14698749.2012.04404.x)

29 Bucher H \& Illig R. Intellectual, school and occupational performance in patients with idiopathic hypothalamo-pituitary hypothyroidism and primary hypothyroidism. Helvetica Paediatrica Acta 198035 489-500.

30 Pollitt E \& Money J. Studies in the psychology of dwarfism. I. Intelligence quotient and school achievement. Journal of Pediatrics 196464 415-421. (https://doi.org/10.1016/s00223476(64)80194-3)

31 Frankel JJ \& Laron Z. Psychological aspects of pituitary insufficiency in children and adolescents with special reference to growth hormone. Israel Journal of Medical Sciences 19684 953-961.
32 Rosenbloom AL, Smith DW \& Loeb DG. Scholastic performance of short-statured children with hypopituitarism. Journal of Pediatrics 196669 1131-1133. (https://doi.org/10.1016/s00223476(66)80307-4)

33 Meyer-Bahlburg HF, Feinman JA, MacGillivray MH \& Aceto T Jr. Growth hormone deficiency, brain development, and intelligence. American Journal of Diseases of Children 1978132 565-572. (https:// doi.org/10.1001/archpedi.1978.02120310029005)

34 Karges B, LeHeup B, Schoenle E, Castro-Correia C, Fontoura M, Pfaffle R, Andler W, Debatin KM \& Karges W. Compound heterozygous and homozygous mutations of the TSHbeta gene as a cause of congenital central hypothyroidism in Europe. Hormone Research 200462 149-155. (https://doi.org/10.1159/000080071)

35 Kempers MJ, van der Sluijs Veer L, Nijhuis-van der Sanden RW, Lanting CI, Kooistra L, Wiedijk BM, Last BF, de Vijlder JJ, Grootenhuis MA \& Vulsma T. Neonatal screening for congenital hypothyroidism in the Netherlands: cognitive and motor outcome at 10 years of age. Journal of Clinical Endocrinology and Metabolism 2007 92 919-924. (https://doi.org/10.1210/jc.2006-1538)

36 Sandberg DE, MacGillivray MH, Clopper RR, Fung C, LeRoux L \& Alliger DE. Quality of life among formerly treated childhood-onset growth hormone-deficient adults: a comparison with unaffected siblings. Journal of Clinical Endocrinology and Metabolism $1998 \mathbf{8 3}$ 1134-1142. (https://doi.org/10.1210/jcem.83.4.4712)

37 Lagrou K, Xhrouet-Heinrichs D, Massa G, Vandeweghe M, Bourguignon JP, De Schepper J, de Zegher F, Ernould C, Heinrichs C, Malvaux P et al. Quality of life and retrospective perception of the effect of growth hormone treatment in adult patients with childhood growth hormone deficiency. Journal of Pediatric Endocrinology and Metabolism 2001 14(Supplement 5) 1249-1260; discussion 61-62.

38 Yuen KC, Koltowska-Haggstrom M, Cook DM, Fox JL, Jonsson PJ, Geffner ME \& Abs R. Clinical characteristics and effects of GH replacement therapy in adults with childhood-onset craniopharyngioma compared with those in adults with other causes of childhood-onset hypothalamic-pituitary dysfunction. European Journal of Endocrinology 2013169 511-519. (https://doi.org/10.1530/ EJE-13-0280)

39 Joustra SD, Andela CD, Oostdijk W, van Trotsenburg AS, Fliers E, Wit JM, Pereira AM, Middelkoop HA \& Biermasz NR. Mild deficits in attentional control in patients with the IGSF1 deficiency syndrome. Clinical Endocrinology 201684 896-903. (https://doi.org/10.1111/ cen.12947)

40 van Tijn DA, de Vijlder JJ, Verbeeten BJ, Verkerk PH \& Vulsma T. Neonatal detection of congenital hypothyroidism of central origin. Journal of Clinical Endocrinology and Metabolism 200590 3350-3359. (https://doi.org/10.1210/jc.2004-2444)

41 Nebesio TD, McKenna MP, Nabhan ZM \& Eugster EA. Newborn screening results in children with central hypothyroidism. Journal of Pediatrics 2010156 990-993. (https://doi.org/10.1016/j. jpeds.2009.12.011)

42 Joustra SD, Heinen CA, Schoenmakers N, Bonomi M, Ballieux BE, Turgeon MO, Bernard DJ, Fliers E, van Trotsenburg AS, Losekoot M et al. IGSF1 deficiency: lessons from an extensive case series and recommendations for clinical management. Journal of Clinical Endocrinology and Metabolism 2016101 1627-1636. (https://doi. org/10.1210/jc.2015-3880)

43 Zwaveling-Soonawala N, van Trotsenburg ASP \& Verkerk PH. TSH and FT4 concentrations in congenital central hypothyroidism and mild congenital thyroidal hypothyroidism. Journal of Clinical Endocrinology and Metabolism 2018103 1342-1348. (https://doi. org/10.1210/jc.2017-01577)

44 Tillotson SL, Fuggle PW, Smith I, Ades AE \& Grant DB. Relation between biochemical severity and intelligence in early treated congenital hypothyroidism: a threshold effect. BMJ 1994309 440-445. (https://doi.org/10.1136/bmj.309.6952.440) 
45 Hanna CE, Krainz PL, Skeels MR, Miyahira RS, Sesser DE \& LaFranchi SH. Detection of congenital hypopituitary hypothyroidism: ten-year experience in the Northwest Regional Screening Program. Journal of Pediatrics 1986109 959-964. (https:// doi.org/10.1016/s0022-3476(86)80276-1)

46 Garcia-Filion P, Epport K, Nelson M, Azen C, Geffner ME, Fink C \& Borchert M. Neuroradiographic, endocrinologic, and ophthalmic correlates of adverse developmental outcomes in children with optic nerve hypoplasia: a prospective study. Pediatrics 2008121 e653-e659. (https://doi.org/10.1542/peds.2007-1825)

47 Oerbeck B, Sundet K, Kase BF \& Heyerdahl S. Congenital hypothyroidism: influence of disease severity and L-thyroxine treatment on intellectual, motor, and school-associated outcomes in young adults. Pediatrics 2003112 923-930. (https://doi.org/10.1542/ peds.112.4.923)

48 Lyman GH \& Kuderer NM. The strengths and limitations of metaanalyses based on aggregate data. BMC Medical Research Methodology 20055 14. (https://doi.org/10.1186/1471-2288-5-14)

49 Floyd RG, Clark MH \& Shadish WR. The exchangeability of IQs: implications for professional psychology. Professional Psychology: Research and Practice 200839 414-423. (https://doi. org/10.1037/0735-7028.39.4.414)

50 Hagmann-von Arx P, Lemola S \& Grob A. Does IQ=IQ? Comparability of intelligence test scores in typically developing children. Assessment 201825 691-701. (https://doi. org/10.1177/1073191116662911)

Received 30 October 2019

Revised version received 15 January 2020

Accepted 21 January 2020 